\title{
Effect of Duration of Muscle Relaxation during Intermittent Isometric Exercises on Deoxygenation and Lactate Accumulation in Active Muscles
}

\author{
YUTAKA TAKUMA, RPT, MS ${ }^{1)}$, TOMOAKI SHIMADA, RPT, PhD²) \\ 1) Department of Physical Therapy, Tosa Rehabilitation College: 2500-2 Otsu, Ohtsu, Kochi 781-5103, \\ Japan. TEL: +81 88-866-6119, FAX: +81 88-866-6120, E-mail: ptrc.takuma@tosareha.ac.jp \\ 2) Department of Rehabilitation Science, Kobe University Graduate School of Health Sciences
}

\begin{abstract}
Purpose] The objective of this study was to investigate the effect of the duration of muscle relaxation during intermittent isometric exercises (IIEs). [Subjects] Subjects were twelve healthy males. [Methods] The subjects performed 10 cycles of intermittent isometric knee extension at $60 \%$ maximum voluntary contraction for 8 seconds. One cycle of IIE consisted of a muscle contraction phase and subsequent muscle relaxation phase. To determine the durations of the muscle relaxation phase, two recovery periods $\left(T_{R 1.0}\right.$ and $\left.T_{R 0.5}\right)$ of oxygenation level in the vastus lateralis muscle (VL) were measured with near-infrared spectroscopy immediately after the isometric knee extension. $\mathrm{T}_{\mathrm{R} 1.0}$ and $\mathrm{T}_{\mathrm{R} 0.5}$ were $30.6 \pm 6.8$ seconds and $15.4 \pm 4.8$ seconds, respectively. Therefore, IIEs were performed as two different types (IIE- $\mathrm{T}_{\mathrm{R} 1.0}$ and IIE- $\mathrm{T}_{\mathrm{R} 0.5}$ ). [Results] Deoxygenation during muscle contraction and relaxation phases in VL were significantly stronger in IIE- $T_{R 0.5}$ than in IIE- $T_{R 1.0}$. The reduction in median power frequency, an indirect measure of lactate accumulation in VL, was also significantly greater in IIE- $\mathrm{T}_{\mathrm{R} 0.5}$ than in IIE- $\mathrm{T}_{\mathrm{R} 1.0}$. [Conclusion] The results of this study suggest that the duration of muscle relaxation determines both deoxygenation and lactate accumulation in active muscles during IIE. Key words: Intermittent isometric exercise, Deoxygenation, Lactate accumulation
\end{abstract}

(This article was submitted Dec. 10, 2010, and was accepted Jan. 20, 2011)

\section{INTRODUCTION}

Isometric exercise, which is static and does not need joint movement, is performed by those who experience pain on joint movement or who need to limit joint movement in order to rest an area of the body. Therefore, isometric exercises are often used in muscle training, or as part of physical therapy for recovery of motor function. Isometric muscle training can be conducted using the correlation of applied load intensity [\% maximum voluntary contraction (MVC)] and duration of muscle contraction, as proposed by Hettinger $^{1)}$, i.e. an intensity of $40 \%-50 \% \mathrm{MVC}$ for $15-20 \mathrm{~s}$, $60 \%-70 \% \mathrm{MVC}$ for $6-10 \mathrm{~s}, 80 \%-90 \% \mathrm{MVC}$ for $4-6 \mathrm{~s}$, or $100 \%$ MVC for $2-3 \mathrm{~s}$.

Unlike isotonic exercise, in which the blood flow in the muscle vasculature is driven by the muscle pump effect, the blood flow in active muscles during isometric muscle training, by which sustained contraction of these muscles is maintained, can be blocked if the load exceeds a certain level. This blockage occurs mainly because of an increase in intramuscular pressure ${ }^{2,3)}$. Intramuscular pressure depends on the tension and morphology of the muscle fibers (e.g. the thickness and curvature of the muscle layers) ${ }^{4}$. Therefore, in many cases, the load that blocks the muscle blood flow varies among the muscles within a range of $50 \%-60 \% \mathrm{MVC}^{5}$.

In general, isometric muscle training in physical therapy is conducted as an intermittent isometric exercise (IIE), often at a moderate load, to increase muscle strength. According to the correlation of load intensity and duration of muscle contraction proposed by Hettinger, the duration of muscle contraction should be $6-10 \mathrm{~s}$ if a mediumintensity load of $60 \%-70 \%$ MVC is applied. Therefore, IIE with this load and duration of muscle contraction would completely or almost completely block the muscle blood flow in active muscles during contraction, even if there is intervening muscle relaxation for a certain period of time. This may result in repeated imbalance between oxygen supply and consumption in active muscles, resulting in gradually increasing deoxygenation. Also, isometric exercise associated with blocked muscle blood flow would create greater dependence of energy supply on glycolysis, resulting in increased production of lactate in active muscles ${ }^{6,7)}$. Blockage of muscle blood flow would prevent this lactate from flowing out of the muscles ${ }^{8}$. Therefore, lactate would gradually accumulate in the muscles during performance of IIE.

During the muscle relaxation phase of IIE, relief of the 
mechanical compression of the muscle vasculature resulting from the increase in intramuscular pressure and exercise hyperaemia ${ }^{9,10)}$ would cause a temporary increase in muscle blood flow, to a level exceeding that at rest before exercise. The increased muscle blood flow supplies the muscles with large amounts of oxygen and removes the accumulated lactate from the muscles. Therefore, deoxygenation and lactate accumulation in active muscles caused by IIE may be influenced not only by the exercise load and the duration of muscle contraction, but also by the duration of the muscle relaxation phase that occurs between muscle contractions.

In this study, we investigated the effect of the duration of the muscle relaxation phase in IIE with a moderate load on deoxygenation and lactate accumulation in active muscles. To this end, we noninvasively examined the oxygenation level and lactate accumulation in the vastus lateralis, which is part of quadriceps femoris muscle, with spatially resolved near-infrared spectroscopy and frequency analysis of a surface electromyogram during intermittent isometric knee extension.

\section{SUBJECTS AND METHODS}

\section{Subjects}

The subjects were 12 healthy males who did not engage in regular exercise. Their age was $21.9 \pm 2.0$ years [mean and standard deviation (SD)]; height, $170.9 \pm 7.0 \mathrm{~cm}$; body weight, $64.6 \pm 9.0 \mathrm{~kg}$; and body mass index $22.1 \pm 2.1 \mathrm{~kg} /$ $\mathrm{m}^{2}$. Subjects were informed of the objective, methods, and potential risks of the study before they consented to participate.

\section{Methods}

The oxygenation level of the right vastus lateralis muscle (VL) was measured together with the recording of a surface electromyogram of this muscle during intermittent isometric knee extension.

The muscle oxygenation level was measured with a nearinfrared spectrometer (OM-220, Shimadzu Corporation, Japan). A probe was attached by an elastic belt to the skin over the muscle belly of VL (distally $1 / 3$ between the greater trochanter and lateral femoral condyle, and laterally $1 / 3$ of the anterior surface of the thigh area). The sampling time was $1 \mathrm{~s}$. The probe $(58 \times 87 \mathrm{~mm})$ of this spectrometer has a light source and two photodetectors. The wavelengths of near-infrared semiconductor laser emitted from the light source are 780 and $830 \mathrm{~nm}$, and the distances between the light source and each photodetector are 25 and $40 \mathrm{~mm}$. This multi-distance spectrometer can determine the oxygenation hemoglobin index (OHI) and deoxygenation hemoglobin index (DHI) (representing the absolute amounts of oxygenated and deoxygenated hemoglobin, respectively, in the muscle tissue) using spatially resolved spectroscopy ${ }^{11,12)}$. In addition, this spectrometer can determine the tissue hemoglobin index (THI) as the sum of these indices and the tissue oxygenation index (TOI) as the proportion of OHI to THI. TOI represents the balance between oxygen supply and consumption in local muscle tissue, and THI represents the blood volume at the same site $^{13,14)}$; therefore, the former is an index of muscle oxygenation level and the latter is an index of exercise hyperaemia.

In preparation for electromyography, we used alcohol to cleanse the skin area where the electrodes were to be placed and rubbed the skin with preparation gel (SkinPure, Nihon Kohden Corp., Japan) to reduce the skin impedance to the electrodes. We used disposable surface recording electrodes (silver-silver chloride with a diameter of $10 \mathrm{~mm}$, Sunnyrode II, Fukuda Denshi Co., Ltd., Japan). For bipolar recording, a pair of recording electrodes, with an inter-electrode distance of $25 \mathrm{~mm}$, was attached to the skin, longitudinally to the muscle fibers. They were positioned proximal to where the probe of the near-infrared spectrometer was fixed to the skin over the muscle belly of VL.

To measure surface electromyogram signals, we used a telemetric electromyograph (CW-1800, Anima Corp., Japan) consisting of recording electrodes, small amplifier, transmitter, receiver, A/D converter, and personal computer (PC). Analog signals were obtained from the recording electrode and loaded on to the PC after they had been subjected to $\mathrm{A} / \mathrm{D}$ conversion at a sampling frequency of 1 $\mathrm{KHz}$. The electromyogram patterns recorded on the PC were passed through a $25-200 \mathrm{~Hz}$ bandpass filter with an analysis time interval of $2048 \mathrm{~ms}$ between 5000 and 7048 $\mathrm{ms}$ after the onset of muscle contraction per session of $8 \mathrm{~s}$ isometric knee extension. The frequency power spectrum was determined through fast-Fourier-transform processing (Hamming window function, 1024-point FFT) to calculate the median power frequency (MdPF). We used a signal analysis program (Bimutas II, Kissei Comtec Co., Ltd., Japan) for this analysis. A shifting of MdPF to a lower frequency suggests an increase of lactate accumulation in the muscles ${ }^{15,16)}$ and this change was therefore used as an index of lactate accumulation in active muscles.

We decided to conduct intermittent isometric knee extension at a target muscle strength of $60 \% \mathrm{MVC}$ with a muscle contraction time of $8 \mathrm{~s}$.

To determine the target muscle strength corresponding to $60 \% \mathrm{MVC}$, the maximum muscle strength (100\% MVC) was measured during isometric knee extension in the subjects. Subjects sat on the seat of a torque machine (Cybex 770, Lumex Inc., USA), to which they were attached by belts over the trunk and pelvis. The hip on the measurement side was held at $80^{\circ}$ and the knee at $60^{\circ}$ (anatomical position $=0^{\circ}$ ). Resistance against knee extension was then applied to the distal end of the lower leg. Muscle strength was measured three times with rests of at least $5 \mathrm{~min}$ before the next measurement. The highest measurement was chosen as $100 \%$ MVC.

There is no reference duration of muscle relaxation in IIE. Therefore, to obtain a suitable reference, we measured $\mathrm{OHI}{ }^{17,18)}$, taking the recovery period to represent the rate of disappearance of deoxygenation in active muscles. Using the same torque machine as the one used to measure $100 \%$ MVC, subjects performed isometric knee extension at $60 \%$ MVC for $8 \mathrm{~s}$ to record the curve of OHI representing the oxygenation level in VL. We then determined the time 


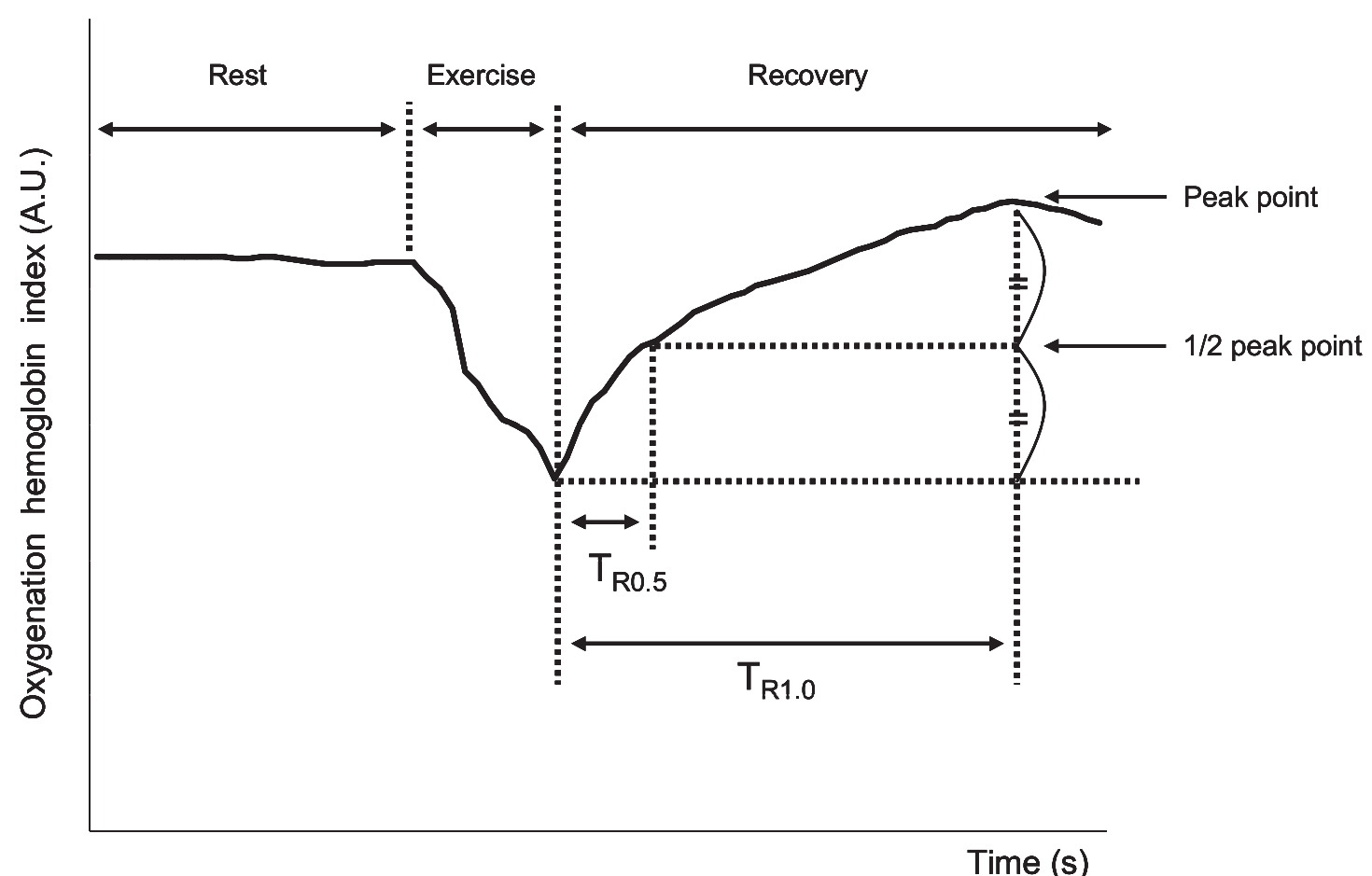

Fig. 1. A typical example of the determination of the recovery periods of the oxygenation hemoglobin index (OHI) in the vastus lateralis muscle. AU : arbitrary unit.

period of the curve between the point when isometric knee extension was stopped and the peak point of $\mathrm{OHI}$ thereafter $\left(\mathrm{T}_{\mathrm{R} 1.0}\right)$, and the time period between the former point and the $1 / 2$ peak point $\left(T_{R 0.5}\right)$; these periods were regarded as the OHI recovery periods (Fig. 1). The recovery periods were measured three times, and the medians of three measurements of $\mathrm{T}_{\mathrm{R} 1.0}$ and $\mathrm{T}_{\mathrm{R} 0.5}$ were taken as the duration of muscle relaxation. Subjects were rested for at least $5 \mathrm{~min}$ between measurements.

One cycle of IIE consisted of a muscle contraction phase and subsequent muscle relaxation phase. The relative duration of the muscle contraction phase in a single cycle was confirmed by calculating the duty cycle ratio $=$ muscle contraction time / (contraction time + relaxation time $)^{19)}$.

IIEs were performed as two different types (IIE- $\mathrm{T}_{\mathrm{R} 1.0}$ and IIE- $\mathrm{T}_{\mathrm{R} 0.5}$ ) of intermittent isometric knee extension. Each IIE was performed 10 cycles, with 5-min rest before the performance. IIE- $\mathrm{T}_{\mathrm{R} 1.0}$ and IIE- $\mathrm{T}_{\mathrm{R} 0.5}$ were performed in randomized order several days apart. Feedback on target muscle strength, duration of the muscle contraction phase, and duration of the muscle relaxation phase was given by information shown on the computer display of the torque machine.

Exercise amount may influence oxygenation level and lactate accumulation in active muscles; therefore, the total work output (TWO; Byström and Kilbom ${ }^{9)}$ ) was calculated as an index of the amount of IIE using the following equation:

$\mathrm{TWO}=\mathrm{m} \cdot \mathrm{t} \cdot \mathrm{f}$

Where, $\mathrm{m}$ is $60 \% \mathrm{MVC}$, $\mathrm{t}$ is the time taken to complete 10 cycles of IIE ( $\mathrm{min}$ ), and $\mathrm{f}$ is the duty cycle ratio.

The duration of the muscle relaxation phase, duty cycle ratio, and TWO were compared between IIE- $\mathrm{T}_{\mathrm{R} 1.0}$ and IIE$\mathrm{T}_{\mathrm{R} 0.5 \text {. }}$

TOI was divided into three phases: rest, muscle contraction, and muscle relaxation. The contraction and relaxation phases were grouped into the first five and second five cycles of the IIE. The representative TOI at rest (baseline) was the mean during a period of $60 \mathrm{~s}$ immediately before IIE. Mean TOIs were calculated for the muscle contraction and relaxation phases, after excluding the first second of each phase. These mean values were then used to calculate the mean TOI in both the contraction and the relaxation phases in the first five cycles (the first mean) and the second five cycles (the second mean). These values were expressed as deviations $(\Delta \mathrm{TOI})$ from the baseline. The baseline, the first mean, and the second mean were compared in the muscle contraction and relaxation phases. The first and second means of the muscle contraction and relaxation phases were also compared between IIE- $\mathrm{T}_{\mathrm{R} 1.0}$ and IIE- $\mathrm{T}_{\mathrm{R} 0.5}$.

The baseline THI and the first and second mean THIs in the muscle relaxation phase were taken as representative. These mean values were calculated in the same manner as that for TOIs. The first and second means were expressed as $\%$ THI through normalization against the baseline (=100\%). Baseline, the first mean, and the second mean were compared. The first and second means were also compared between IIE- $\mathrm{T}_{\mathrm{R} 1.0}$ and IIE- $\mathrm{T}_{\mathrm{R} 0.5}$. 
MdPF in the first cycle of IIE was taken as the baseline. The mean MdPF in the fourth and fifth cycles was the first mean, and the mean MdPF in the ninth and 10th cycles was taken as the second mean. These three were representative values. The first and second means were expressed as $\% \mathrm{MdPF}$ through normalization against the baseline (= $100 \%)$. We then compared the baseline and first and second means. The first and second means were also compared between IIE- $\mathrm{T}_{\mathrm{R} 1.0}$ and IIE- $\mathrm{T}_{\mathrm{R} 0.5}$.

All comparisons were conducted using two-way analysis of variance. Statistical significance was tested by multiple comparison (Scheffe's F-test). The paired t-test was used to compare two groups. In all analyses, a P value less than 5\% was considered to indicate statistical significance.

\section{RESULTS}

All results are expressed as means $\pm \mathrm{SD}$.

We found that $100 \% \mathrm{MVC}$ was $272.3 \pm 68.9 \mathrm{Nm}(4.2 \pm$ $0.6 \mathrm{Nm} / \mathrm{kg}$ ) and $60 \% \mathrm{MVC}$ (the target muscle strength) was $163.6 \pm 41.4 \mathrm{Nm}(2.5 \pm 0.4 \mathrm{Nm} / \mathrm{kg})$.

Table 1 shows the duration of the muscle relaxation phase and duty cycle ratio, and TWO, during IIE.
Significant differences were observed in the duration of the muscle relaxation phase and the duty cycle ratio between IIE- $_{\mathrm{R} 1.0}$ and IIE- $\mathrm{T}_{\mathrm{R} 0.5}$ (both $\mathrm{p}<0.01$ ).

Table 2 shows $\Delta$ TOI in IIE- $\mathrm{T}_{\mathrm{R} 1.0}$ and IIE-T $\mathrm{T}_{\mathrm{R} 0.5}$. In IIE$\mathrm{T}_{\mathrm{R} 1.0}$, the first $(\mathrm{p}<0.05)$ and second $(\mathrm{p}<0.01) \Delta \mathrm{TOIs}$ in the muscle contraction phase were significantly lower than at baseline. The second $\Delta$ TOI was significantly more negative than the first one $(p<0.01)$. The first $(p<0.01)$ and second $(\mathrm{p}<0.01) \Delta$ TOIs in the muscle relaxation phase were also significantly more negative than at baseline. No significant difference was observed between the first and second $\Delta$ TOIs. In IIE- $\mathrm{T}_{\mathrm{R} 0.5}$, the first $(\mathrm{p}<0.01)$ and second $(\mathrm{p}<$ $0.01) \Delta$ TOIs in the muscle contraction phase were significantly more negative than at baseline. The second $\Delta$ TOI was significantly more negative than the first ( $p<$ $0.05)$. The first $(\mathrm{p}<0.01)$ and second $(\mathrm{p}<0.01) \Delta$ TOIs in the muscle relaxation phase were significantly more negative than at baseline. No significant difference was observed between the first and second $\Delta$ TOIs. The first $(\mathrm{p}<$ $0.01)$ and second $(p<0.05) \Delta$ TOIs during the muscle contraction phase were significantly more negative in IIE$\mathrm{T}_{\mathrm{R} 0.5}$ than in IIE- $\mathrm{T}_{\mathrm{R} 1.0}$. Similarly, the first $(\mathrm{p}<0.01)$ and second $(\mathrm{p}<0.01) \Delta$ TOIs during the muscle relaxation phase

Table 1. Comparison of conditions between IIE $-\mathrm{T}_{\mathrm{R} 1.0}$ and IIE $-\mathrm{T}_{\mathrm{R} 0.5}$

\begin{tabular}{lll}
\hline & \multicolumn{1}{c}{ IIE-T $_{\mathrm{R} 1.0}$} & \multicolumn{1}{c}{ IIE- $_{\mathrm{R} 0.5}$} \\
\hline duration of muscle relaxation phase $(\mathrm{s})$ & $30.6 \pm 6.8$ & $15.4 \pm 4.8^{* *}$ \\
duty cycle ratio & $0.21 \pm 0.04$ & $0.36 \pm 0.07^{* *}$ \\
total work output & $80.0 \pm 0.1$ & $80.0 \pm 0.1$ \\
\hline
\end{tabular}

Values are means $\pm \operatorname{SD}(\mathrm{n}=12)$.

$* * \mathrm{p}<0.01$ : Significant difference from IIE- $\mathrm{T}_{\mathrm{R} 1.0}$.

Table 2. Comparison of $\Delta$ TOI (\%) between IIE - $T_{R 1.0}$ and IIE- $T_{R 0.5}$

\begin{tabular}{lcclcl}
\hline & \multicolumn{3}{c}{ Muscle contraction phase } & & \multicolumn{2}{c}{ Muscle relaxation phase } \\
\cline { 2 - 3 } \cline { 5 - 6 } & First half of IIE & Second half of IIE & & First half of IIE & Second half of IIE \\
\hline IIE-T $_{\mathrm{R} 1.0}$ & $-6.8 \pm 7.0^{*}$ & $-14.9 \pm 9.8^{* *} \# \#$ & & $-8.3 \pm 7.6^{* *}$ & $-11.0 \pm 7.0^{* *}$ \\
IIE-T $_{\mathrm{R} 0.5}$ & $-15.4 \pm 6.8^{* * \$ \$}$ & $-21.2 \pm 8.4 * * \$$ & & $-18.7 \pm 8.7 * * \$$ & $-17.6 \pm 7.4 * * \$ \$$ \\
\hline
\end{tabular}

Values are means $\pm \mathrm{SD}(\mathrm{n}=12)$.

$* \mathrm{p}<0.05, * * \mathrm{p}<0.01$ : Significant difference from baseline (rest).

${ }^{\#} \mathrm{p}<0.05$, $\# \mathrm{p}<0.01$ : Significant difference from first half of IIE.

$\$ p<0.05,{ }^{\$} p<0.01$ : Significant difference from IIE $-T_{R 1.0}$.

Table 3. Comparison of \% THI between IIE $-\mathrm{T}_{\mathrm{R} 1.0}$ and IIE$\mathrm{T}_{\mathrm{R} 0.5}$

\begin{tabular}{lcc}
\hline & First half of IIE & Second half of IIE \\
\hline IIE-T $_{\mathrm{R} 1.0}$ & $106.2 \pm 5.9 * *$ & $106.9 \pm 6.0 * *$ \\
IIE-T $_{\mathrm{R} 0.5}$ & $108.5 \pm 6.9 * *$ & $111.1 \pm 9.2 * * \$$ \\
\hline
\end{tabular}

Values are means $\pm \mathrm{SD}(\mathrm{n}=12)$.

$* * \mathrm{p}<0.01$ : Significant difference from baseline (rest).

$\$ p<0.05$ : Significant difference from second half of IIE $-T_{R 1.0}$.
Table 4. Comparison of $\% \mathrm{MdPF}$ between IIE $-\mathrm{T}_{\mathrm{R} 1.0}$ and IIE $-\mathrm{T}_{\mathrm{R} 0.5}$

End of first half of IIE End of second half of IIE

\begin{tabular}{lll}
\hline${\text { IIE }-\mathrm{T}_{\mathrm{R} 1.0}} 97.8 \pm 9.0^{* *}$ & $98.9 \pm 9.5^{* *}$ \\
IIE-T $_{\mathrm{R} 0.5}$ & $94.3 \pm 5.4^{* *}$ & $93.5 \pm 5.4^{* *} \$$ \\
\hline
\end{tabular}

Values are means $\pm \mathrm{SD}(\mathrm{n}=12)$.

** $p<0.01$ : Significant difference from baseline (first cycle of IIE).

${ }^{\$} p<0.05$ : Significant difference from end of second half of IIE $-T_{R 1.0}$. 
were significantly more negative in IIE- $\mathrm{T}_{\mathrm{R} 0.5}$ than in IIE$\mathrm{T}_{\mathrm{R} 1.0}$.

Table 3 shows the $\%$ THI in IIE-T $\mathrm{T}_{\mathrm{R} 1.0}$ and IIE-T $\mathrm{T}_{\mathrm{R} 0.5}$. The first and second \%THIs were significantly higher than that at baseline in both IIE- $\mathrm{T}_{\mathrm{R} 1.0}$ and IIE- $\mathrm{T}_{\mathrm{R} 0.5}$ (both $\mathrm{p}<0.01$ ). There was no significant difference between the first and second \%THI. No significant difference was observed in the first $\% \mathrm{THI}$ between IIE- $\mathrm{T}_{\mathrm{R} 1.0}$ and IIE- $\mathrm{T}_{\mathrm{R} 0.5}$, although the second \% THI was significantly higher in IIE- $\mathrm{T}_{\mathrm{R} 0.5}$ than in IIE-T $\mathrm{T}_{\mathrm{R} .0}(\mathrm{p}<0.05)$.

Table 4 shows the $\%$ MdPF in IIE- $\mathrm{T}_{\mathrm{R} 1.0}$ and IIE- $\mathrm{T}_{\mathrm{R} 0.5}$. The first and second \%MdPFs were significantly lower than that at baseline in both types of IIE (both $p<0.01$ ). There was no significant difference between the first and second $\%$ MdPF. No significant difference was observed in the first $\% \mathrm{MdPF}$ between IIE- $\mathrm{T}_{\mathrm{R} 1.0}$ and IIE- $\mathrm{T}_{\mathrm{R} 0.5}$, although the second $\% \mathrm{MdPF}$ was significantly lower in IIE- $\mathrm{T}_{\mathrm{R} 0.5}$ than in IIE-T $_{\text {R1.0 }}(\mathrm{p}<0.05)$.

\section{DISCUSSION}

In accordance with the combinations of load and duration of muscle contraction proposed by Hettinger for isometric muscle training, our subjects performed IIE at a moderate strength of $60 \% \mathrm{MVC}$ with a muscle contraction time of $8 \mathrm{~s}$. The objective of this study was to noninvasively investigate the effect of various periods of muscle relaxation time between muscle contraction phases in an IIE session on deoxygenation and lactate accumulation in active muscles. There is no reference duration of muscle relaxation in IIE. Therefore, to determine an appropriate one, we measured the recovery period of $\mathrm{OHI}$, representing the rate of disappearance of deoxygenation in the subjects' active muscles ${ }^{17,18)}$. Then, $T_{R 1.0}$ and $T_{R 0.5}$ were determined for use in the evaluation of muscle relaxation in IIE.

TOI in the muscle contraction phase was significantly more negative in the first and second IIE- $\mathrm{T}_{\mathrm{R} 1.0}$ and IIE- $\mathrm{T}_{\mathrm{R} 0.5}$ than at baseline. VL was experiencing deoxygenation ${ }^{13)}$, indicating that there was an imbalance between oxygen supply and consumption in the muscle contraction phase of the first and second halves of IIE.

The muscle oxygenation level is associated with arterial influx, venous return, and oxygen extraction in muscles ${ }^{20)}$. Therefore, the deoxygenation in VL during the muscle contraction phase reflects changes in these mechanisms.

Greig et al. ${ }^{21)}$ demonstrated that almost all muscle fibers in VL are recruited at about $50 \%$ of maximum muscle strength and that both type I and II muscle fibers were activated. Thus, both aerobic and glycolytic metabolism are activated in VL at a moderate load with increases in oxygen consumption and production of lactate occurring simultaneously during IIE at $60 \%$ MVC. In addition, the limited oxygen supply caused by a decrease in muscle blood flow may lead to the production of lactate during isometric exercise $e^{6,7)}$.

Sadamoto et al. ${ }^{5)}$ reported that isometric muscle strength was proportional to intramuscular pressure and that muscle blood flow was arrested in VL at a mean increased intramuscular pressure of $64 \%$ MVC. Therefore, oxygen supply via arterial influx and lactate outflow via venous return are simultaneously prevented from occurring during the muscle contraction phase.

Deoxygenation during the muscle contraction phase might be caused by the intermittent oxygen deficiency in active muscles that occurs after the oxygen supply becomes limited through increased oxygen consumption. Also, an imbalance between production and outflow of lactate occurs intermittently, suggesting that lactate may gradually accumulate in VL. Acidification of active muscles through lactate accumulation (lactic acidosis) may accelerate oxygen release from hemoglobin, resulting in increased oxygen extraction from the muscles ${ }^{20,22)}$. Therefore, lactate accumulation in VL may be closely involved in the deoxygenation of muscles.

The deoxygenation occurring during the muscle contraction phase was significantly extended in the second half compared with the first half in both IIE- $\mathrm{T}_{\mathrm{R} 1.0}$ and IIE$\mathrm{T}_{\mathrm{R} 0.5}$. This may be explained by the intermittent repetition of isometric exercise, causing deoxygenation during the muscle contraction phase without reoxgenation during the muscle relaxation phase, together with the presumed accumulation of lactate.

TOI during the muscle relaxation phase remained significantly decreased in the first and second halves of both IIE- $_{R 1.0}$ and IIE- $T_{R 0.5}$. THI, which may influence the oxygenation level during the muscle relaxation phase, significantly increased in the first and second halves of both IIE- $_{\mathrm{R} 1.0}$ and IIE- $\mathrm{T}_{\mathrm{R} 0.5}$. IIEs in this study caused an increase in blood volume in VL during the muscle relaxation phase compared with that at baseline, although no improvement in muscle deoxygenation was observed.

A transient increase in muscle blood volume immediately after contraction is associated with exercise hyperaemia ${ }^{13,23)}$. Exercise hyperaemia is caused by the accumulation of vasodilator metabolites (e.g. lactate, potassium, and inorganic phosphate) produced in active muscles, as well as by a reduction in $\mathrm{PO} 2$ and $\mathrm{pH}^{9,10)}$. Production of vasodilator metabolites is markedly increased at a muscle contraction strength of $25 \%$ MVC or higher ${ }^{9}$. Therefore, muscle deoxygenation and lactate accumulation may induce exercise hyperaemia. Exercise hypearemia may cause an increase in muscle blood flow, followed by acceleration of both oxygen supply to the active muscles during the muscle relaxation phase of IIEs and the outflow of metabolites from these muscles. However, no improvement was observed in deoxygenation during the first and second halves of the muscle relaxation phase; therefore, oxygen consumption surpassed the oxygen supply delivered by exercise hyperaemia in VL during the relaxation phase. This increment in oxygen consumption causes an oxygen deficit during the muscle relaxation phase. The deficit may therefore prevent reoxygenation during the muscle relaxation phase. In addition, lactate is not necessarily removed completely from VL during the muscle relaxation phase, despite the fact that an increase in muscle blood flow can accelerate the outflow of metabolites. Therefore, the remaining acidosis caused by the incomplete removal of lactate promotes oxygen 
extraction from the active muscles, and this in turn might delay the improvement of muscle deoxygenation.

$\mathrm{MdPF}$, an indirect parameter of lactate accumulation in $\mathrm{VL}$, was significantly reduced at the end of the first and second halves of both IIE-T $\mathrm{T}_{\mathrm{R} 1.0}$ and IIE-T $\mathrm{T}_{\mathrm{R} 0.5}$. MdPF might shift toward a lower frequency as a result of accumulation of lactate and other metabolites in the active muscles, followed by a reduction in muscle $\mathrm{pH}$, leading to a decrease in the rate of conduction of action potentials in muscle fibers ${ }^{15,16)}$. Miura et al. ${ }^{20}$ ) reported that the muscle oxygenation level, as evaluated by near-infrared spectroscopy, was closely correlated with blood lactate concentration, indicating that deoxygenation reflects the presence of lactic acidosis in active muscles. Hicks et al. ${ }^{24)}$ found relationships between the presence of deoxygenation in active muscles and reductions in MdPF and increases in blood lactate level. Muscle deoxygenation and reduction in MdPF were simultaneously observed during both IIE- $\mathrm{T}_{\mathrm{R} 1.0}$ and IIE- $\mathrm{T}_{\mathrm{R} 0.5}$, suggesting that lactate accumulated in VL during the first and second halves of IIEs.

Deoxygenation in the first and second halves of the muscle contraction and relaxation phases in IIE were significantly stronger in IIE- $\mathrm{T}_{\mathrm{R} 0.5}$ than in IIE- $\mathrm{T}_{\mathrm{R} 1.0}$. Although there was no significant difference in lactate accumulation and exercise hyperaemia between IIE- $T_{R 1.0}$ and IIE- $\mathrm{T}_{\mathrm{R} 0.5}$ in the first half of the IIE, in the second half of IIE they were significantly greater in IIE- $\mathrm{T}_{\mathrm{R} 0.5}$ than in IIE- $_{\mathrm{R} 1.0}$. As described earlier, muscle deoxygenation, lactate accumulation, and exercise hyperaemia were highly associated in terms of their mechanisms of development, resulting in significantly greater values in IIE- $_{\mathrm{R} 0.5}$ than in IIE- $_{\mathrm{R} 1.0}$.

IIE- $\mathrm{T}_{\mathrm{R} 1.0}$ and IIE- $\mathrm{T}_{\mathrm{R} 0.5}$ had similar conditions of intermittent isometric exercise, including load, duration of the muscle contraction phase, number of repeats, and TWO. However, they also had different conditions, including duration of the muscle relaxation phase and duty cycle ratio.

An abbreviated equation for TWO by Byström and Kilbom $^{9)}$ is the product of load and total duration of the muscle contraction phase, indicating that TWO is an index of the amount of IIE. The mean TWO was 80.0 in both IIE$\mathrm{T}_{\mathrm{R} 1.0}$ and IIE- $\mathrm{T}_{\mathrm{R} 0.5}$, suggesting that the amount of IIE was the same in IIE- $\mathrm{T}_{\mathrm{R} 1.0}$ and IIE- $\mathrm{T}_{\mathrm{R} 0.5}$. Therefore, the amount of IIE cannot explain the significant difference in muscle deoxygenation, lactate accumulation, and exercise hyperaemia between IIE- $\mathrm{T}_{\mathrm{R} 1.0}$ and IIE- $\mathrm{T}_{\mathrm{R} 0.5}$.

There were significant differences in duration of the muscle relaxation phase and duty cycle ratio between IIE$\mathrm{T}_{\mathrm{R} 1.0}$ and IIE- $\mathrm{T}_{\mathrm{R} 0.5}$. The mean duration was $30.6 \mathrm{~s}$ and the mean duty cycle ratio was 0.21 in IIE- $T_{R 1.0}$, and the equivalent values in IIE- $\mathrm{T}_{\mathrm{R} 0.5}$ were $15.4 \mathrm{~s}$ and 0.36 , respectively. The duration of the muscle relaxation phase was significantly shorter (about $1 / 2$ ), and the duty cycle ratio significantly greater (about 1.7 fold) in IIE- $\mathrm{T}_{\mathrm{R} 0.5}$ than in IIE- $T_{R 1.0}$. Therefore, we consider that these significant differences in the duration of the muscle relaxation phase and in the duty cycle ratio explain the significant difference in muscle deoxygenation, lactate accumulation, and exercise hyperaemia between IIE- $\mathrm{T}_{\mathrm{R} 1.0}$ and IIE- $\mathrm{T}_{\mathrm{R} 0.5}$.

The exercise hyperaemia in the first and second halves of IIE- $\mathrm{T}_{\mathrm{R} 1.0}$ and IIE- $\mathrm{T}_{\mathrm{R} 0.5}$ suggests an increase in muscle blood flow in the muscle relaxation phases of both IIE- $\mathrm{T}_{\mathrm{R} 1.0}$ and IIE-T $\mathrm{T}_{\mathrm{R} 0.5}$. An increase in muscle blood flow caused by exercise hyperaemia promotes oxygen supply to active muscles via arterial influx and outflow of lactate from the muscles via venous return. In turn, shorter duration of the muscle relaxation phase and/or less exercise hyperaemia in IIE may be unfavorable for delivering such benefits. An increase in the duty cycle ratio may increase the relative duration of the muscle contraction phase and decrease the relative duration of the muscle relaxation phase, leading to effects of exercise hyperaemia similar to those observed during the shorter muscle relaxation phase of IIE. Although the degree of exercise hyperaemia was slightly higher in IIE- $\mathrm{T}_{\mathrm{R} 0.5}$ than in IIE- $\mathrm{T}_{\mathrm{R} 1.0}$, the resulting benefits of muscle blood flow lasted only about half the length of IIE- $\mathrm{T}_{\mathrm{R} 1.0}$, causing the relationships between oxygen supply and consumption and between production and removal of lactate to be chronically imbalanced. This might have resulted in the significantly greater muscle deoxygenation, lactate accumulation, and exercise hyperaemia (which depends on the former two) in IIE- $\mathrm{T}_{\mathrm{R} 0.5}$ than in IIE- $\mathrm{T}_{\mathrm{R} 1.0}$.

Dolmage and Cafarelli ${ }^{19)}$ reported that the attenuation of muscle strength caused by IIEs was closely correlated with the product of relative muscle strength (\%MVC) and the duty cycle ratio. Packman-Braun ${ }^{25)}$ reported that muscle fatigue would be likely to occur in response to higher electrical stimuli with a higher duty cycle ratio. These reports suggest that IIE is proportional not only to the strength of muscle contraction but also to the duty cycle ratio. Therefore, in addition to relative muscle strength (representing load), the duty cycle ratio that influences deoxygenation, as well as lactate accumulation in active muscles, may be important determinants of the intensity of IIE.

In conclusion, the results of this study suggest that the duration of the interval of muscle relaxation and the duty cycle ratio (indirectly representing the relative duration of the muscle relaxation phase) are both determinants of the oxygenation level and lactate accumulation in active muscles during intermittent isometric exercise at a moderate load. Intermittent isometric exercise for muscle training should be regulated not only by applied load (\%MVC) and its duration but also by the duration of the muscle relaxation interval and the duty cycle ratio.

\section{REFERENCES}

1) Hettinger T: Isometrisches muskel training. Tokyo: Taisyukan, 1970 , pp108-112 (in Japanese)

2) Nilsson B, Ingvar DH: Intramuscular pressure and contractile strength related to muscle blood flow in man. Scand J Clin Lab Invest Supp, 1967, $93: 31-38$.

3) Bonde-Petersen F, Mork AL, Nielsen E: Local muscle blood flow and sustained contractions of human arm and back muscles. Europ J Appl Physiol, 1975, $34:$ 43-50.

4) Sejersted OM, Hargens AR, Kardel KR, et al.: Intramuscular fluid pressure during isometric contraction of human skeletal muscle. J Appl Physiol, 1984, 56 : 287-295.

5) Sadamoto T, Bonde-Petersen F, Suzuki Y: Skeletal muscle tension, flow, 
pressure, and EMG during sustained isometric contractions in humans. Eur J Appl Physiol Occup Physiol, 1983, 51: 395-408.

6) Katz A, Sahlin K, Henriksson J: Muscle ATP turnover rate during isometric contraction in humans. J Appl Physiol, 1986, 60: 1839-1824.

7) Gentil P, Oliveira E, Bottaro M: Time under tension and blood lactate response during four different resistance training methods. J Physiol Anthropol, 2006, 25: 339-344.

8) Duchateanu J, Montigny LD, Hainaut K: Electro-mechanical failures and lactate production during fatigue. Eur J Appl Physiol, 1987, 56: 287-291.

9) Byström SEG, Kilbom A: Physiological response in the forearm during and after isometric intermittent handgrip. Eur J Appl Physiol, 1990, 60: 457466.

10) Osada $T$, Katsumura $T$, Murase N, et al.: Post-exercise hyperemia after ischemic and non-ischemic isometric handgrip exercise. J Physiol Anthropo Appl human Sci, 2003, 22: 299-309.

11) Matcher SJ, Kirkpatrick P, Nahid K, et al. : Absolute quantification methods in tissue near infrared spectroscopy. Proc Soc Photo-Opt Instrum Eng, 1995, 2389: 486-495.

12) Suzuki S, Takasaki S, Okazaki T, et al.: A tissue oxygenation monitor using NIR spatially resolved spectroscopy. Proc Soc Photo-Opt Instrum Eng, 1999, 3597: 582-592.

13) Quaresima V, Homma S, Azuma K, et al.: Calf and shin muscle oxygenation patterns and femoral artery blood flow during dynamic plantar flexion exercise in humans. Eur J Appl Physiol, 2001, 84: 387-394.

14) Fujimoto $S$, Yoshikawa $T$, Tateishi $Y$, et al.: Evaluation of muscle oxygenation during exercise by NIRS in normal subjects. J Jpn Coll Angiol, 2007, 47: 21-27.

15) Merletti R, Sabbahi MA, Luca CJ: Median frequency of the myoelectric signal effects of muscle ischemia and cooling. Eur J Appl, 1984, 52: 258 265 .
16) Yamada H, Kizuka T, Masuda T, et al.: Evaluation of voluntary muscle activation and tolerance for fatigue using twitch interpolation technique. Jpn J Phys Fitness Sports Med, 2000, 49: 315-328 (in Japanese).

17) Chance B, Dait MT, Zhang C, et al.: Recovery from exrcise-induced desaturation in the quadriceps muscles of elite competitive rowers. J Appl Physiol, 1992, 262: 766-775.

18) Mccully KK, Iotti S, Kendrick K, et al.: Simultaneous in vivo measurements of $\mathrm{Hb} \mathrm{O} 2$ saturation and $\mathrm{PCr}$ kinetics after exercise in normal humans. J Appl Physiol , 1994, 77: 5-10.

19) Dolmage $T$, Cafarelli E: Rate of fatigue during repeated submaximal contractions of human quadriceps muscle. Can J Physiol Pharmacol, 1991, 69: 1410-1415.

20) Miura H, Araki H, Matoba H, et al. : Relationship among oxygenation, myoelectric activity, and lactic acid accumulation in vastus lateralis muscle during exercise with constant work rate. Int J sport Med, 2000, 21: 180-184.

21) Greig C, Sargeant AJ, Vøllestad NK: Muscle force and fiber recruitment during dynamic exercise in man. J physiol, 1985, 371: 176.

22) Grassi B, Quaresima V, Marconi C, et al.: Blood lactate accumulation and muscle deoxygenation during incremental exercise. J Appl Physiol, 1999, 87: 348-355.

23) Miura H, Toiguchi K: Muscle oxygenation, myoelectric activity and oxygen supply in the thigh area during isometric knee-extended exercise. J Jpn Coll Angiol, 2007, 47: 47-51(in Japanese).

24) Hicks A, McGill S, Hughson RL: Tissue oxygenation by near-infrared spectroscopy and muscle blood flow during isometric contrations of the forearm. Can J Appl Physiol, 1999, 24: 216-230.

25) Packman-Braun R: Relationship between functional electrical stimulation duty cycle and fatigue in wrist extensor muscles of patients with hemiparesis. Phys Ther, 1988, 68: 51-56. 